\title{
Comparative Study of Diagnostic Accuracy of Modified Alvarado Score and Ultrasonography in Acute Appendicitis
}

\author{
Dr SATYAJEET KUMAR SINGH, Dr KUNAL, Dr CHITRANGADA.
}

\begin{abstract}
Objective: Comparative study of Diagnostic accuracy of Modified Alvarado Score and Ultrasonography in Acute Appendicitis.Research design and methods: A total of 55 patients of age group between 7-65yrs,both male and females, with clinical features suggestive of acute appendicitis were selected non-randomly for the study.Data was collected as Alvarado score, ultrasonograpic findings and histopathological reports. Statistical analysis was performed and results of both Alvarado score and Ultrasonography were compared.Results: Of 55 patients taken,maximum percentage of patients were in age group 10-20yrs with males dominated the series.The sensitivity and specificity of Modified alvarado score was $82.05 \%$ and $81.25 \%$ with PPV $91.42 \%$ and NPV $65 \%$ and diagnostic accuracy of $81.82 \%$ respectively.Ultrasonography study revealed $84.61 \%$ sensitivity and specificity of 56\%,PPV and NPV were $80.48 \%$ and $57.14 \%$ and diagnostic accuracy was $70.91 \%$ respectively.Conclusions: From present study, it is concluded that Modified Alvarado score is better diagnostic tool than ultrasonography alone in diagnosis of acute appendicitis.
\end{abstract}

Acute appendicitis is one of the commonest surgical emergency. A case of appendicitis can progress to perforation and other life threatening complications, which is associated with much higher morbidity and mortality and the surgeons are left with no option than to operate, when diagnosed clinically rather than to wait until it is confirm. Despite the introduction of various scoring system, extraordinary advances in modern radiographic imaging and diagnostic laboratory investigation, the accurate diagnosis of acute appendicitis remains an enigmatic challenge. A scoring system for early diagnosis of acute appendicitis was developed by Alvarado in 1986; based on clinical signs, symptoms and differential leucocyte count, with a left shift of neutrophil maturation yielding a total score of 10; known as Alvarado score. Kalan et al omitted the left shift to neutrophil maturation parameter and produced a Modified Alvarado score. It is a 9 point scoring system that helps in increasing the accuracy of preoperative diagnosis and thus reducing negative appendicectomy rate. Score of 7 or more were recommened for surgery.

Various radiological imagings like plain X-ray, barium meal follow through, barium enema, graded compression ultrasonography, colour Doppler ultrasonography, CT scan, MRI has been developed for more accurate diagnosis of acute appendicitis; but no one is confirmatory. It has been claimed that ultrasonography dramatically reduce the number of appendicectomy in patients without appendicitis. It is especially useful in children and young thin adults; and in females it will allow exclusion of gynaecological cause with diagnostic accuracy in excess of $90 \%$.

The aim of this study to validate the user friendly pre-operative diagnostic method based on prospectively collected data from patients admitted for suspected appendicitis incorporating the Modified Alvarado Score and graded compression ultrasonography.

\section{Research Design And Methods}

Study population: Patients of all age group varrying between $7-65$ yrs of age,both male and female,presented in casualty department,OPD\&indoor with the clinical features suggestive of acute appendicitis were selected non randomly for the study.

Sample size and sample technique:55 patients selected non randomly.

Data collection technique and tools: Data was collected as Alvarado score,ultrasonographic finding and histopathologicalreports.alvarado score of $>7$ were taken as positive and $<7$ as negative.histopathology showing inflamed appendix were taken as positive an normal appendix as negative.sonographically showing features suggestive of appendicitis in patients with Alvarado score $<7$ were marked positive.

Data analysis:Categorizations of different parameters were performed by simple statistical methods like standard table, Pie diagrams, And Bar charts etc. Statistical analysis was performed using 
Comparative Study Of Diagnostic Accuracy Of Modified Alvarado Score And Ultrasonography In

sensitivity,specificity,positive predictive value,negative predictive value,negative laparotomy rate and diagnostic accuracy,and result of both Alvarado score and ultrasonography were compared.

\section{Results}

The study was conducted on 55 patient suspected of acute appendicitis. Results of all the parameters are as followed :

Result of our treatment plan of score $>7$

\begin{tabular}{|c|c|c|c|c|c|c|c|}
\hline \multirow[t]{2}{*}{ Sex } & \multirow{2}{*}{$\begin{array}{l}\text { Modified } \\
\text { Alvarado } \\
\text { Score }>7\end{array}$} & \multicolumn{2}{|c|}{ USG Positive } & \multicolumn{2}{|c|}{ Treatment Plan } & \multicolumn{2}{|c|}{$\begin{array}{c}\text { Confirmed } \\
\text { Appendicitis }\end{array}$} \\
\hline & & No. & $\%$ & Conservative & Appendicectomy & No. & $\%$ \\
\hline Men & 20 & 15 & 75 & $2 \#$ & 18 & 17 & 95 \\
\hline Female & 15 & 11 & 60 & & 15 & 13 & 86.66 \\
\hline Total & 35 & 26 & 74.2 & & 33 & 32 & 91.42 \\
\hline
\end{tabular}

\#-Patient managed conservatively due to appendicular lump and latter on underwent interval appendicectomy.

Result of our treatment plan of score $<7$

\begin{tabular}{|c|c|c|c|c|c|c|c|}
\hline \multirow[t]{2}{*}{ Sex } & \multirow{2}{*}{$\begin{array}{c}\text { Modified } \\
\text { Alvarado Score } \\
<7\end{array}$} & \multicolumn{2}{|c|}{ USG Positive } & \multicolumn{2}{|c|}{ Treatment Plan } & \multicolumn{2}{|c|}{$\begin{array}{c}\text { Confirmed } \\
\text { Appendicitis }\end{array}$} \\
\hline & & No. & $\%$ & Conservative & Appendicectomy & No. & $\%$ \\
\hline Male & 12 & 9 & 75 & 3 & 9 & 4 & 44 \\
\hline Female & 8 & 6 & 75 & 2 & 6 & 3 & 50 \\
\hline
\end{tabular}

Sensitivity and Specificity of Modified Alvarado Score

\begin{tabular}{|c|c|c|c|}
\hline $\begin{array}{c}\text { Diagnostic Test } \\
\text { Result }\end{array}$ & Appendicitis & Not Appendicitis & Total \\
\hline Score $>7$ Positive & (True positive) & (False positive) & 35 \\
\hline Score $<7$ Negative & (False negative) & (True negative) & 13 \\
& 7 & 16 & 20 \\
\hline Total & 39 & & 55 \\
\hline
\end{tabular}

Sensitivity and Specificity of Ultrasonography

\begin{tabular}{|c|c|c|c|}
\hline $\begin{array}{c}\text { Diagnostic } \\
\text { approach result }\end{array}$ & Appendicitis & Not Appendicitis & Total \\
\hline USG Positive & (True positive) & (False positive) & 41 \\
\hline USG Negative & 33 & 8 & 14 \\
& 8 & (False negative) & 6 \\
\hline Total & 41 & 14 & 55 \\
\hline
\end{tabular}

\begin{tabular}{|c|c|}
\hline ALVARADO SCORE & ULTRASONOGRAPHY \\
\hline $\begin{array}{l}\text { Sensitivity }=32 / 32+7=82.05 \% \\
\text { Specificity }=13 / 13+3=81.25 \% \\
\text { Positive predictive value }=32 / 32+3=91.42 \% \\
\text { Negative predictive value }=13 / 13+7=65 \% \\
\text { Negative appendicectomy rate }=13 / 13+7=8.5 \% \\
\text { Diagnostic accuracy }=32+13 / 55=81.82 \%\end{array}$ & $\begin{array}{l}\text { Sensitivity }=33 / 33+6=84.61 \% \\
\text { Specificity }=8 / 8+8=50 \% \\
\text { Positive predictive value }=33 / 33+8=80.48 \% \\
\text { Negative predictive value }=8 / 8+6=57.14 \% \\
\text { Negative appendicectomy rate }=8 / 33+8=19.51 \% \\
\text { Diagnostic accuracy = } \\
33+6 / 55=70.91 \%\end{array}$ \\
\hline
\end{tabular}




\section{Discussion}

The diagnostic accuracy in cases of acute appendicitis should be high because negative appendicectomy carries significant morbidity as there is a greater risk for abdominal adhesions after appendicectomy. However, the symptoms of appendicitis may not be classical, and in such situation; a policy of early intervention to avoid perforation may lead to high negative appendicectomy rate. Difficulties in diagnosis arise in very young, elderly patients and females of reproductive age because they are more likely to have an atypical presentation, and many other conditions may mimic acute appendicitis in these patients. In such cases, clinical examinations should be complemented with various investigations to exclude other diseases and helpful to achieve a more accurate diagnosis.

Many scoring system for the diagnosis of acute appendicitis have been tried; but most of these are complex and not feasible in emergency setting. Therefore; a scoring system used for the diagnosis of acute appendicitis should be simple enough to be used as an emergency department setting. Modified Alvarado Score is just a simple mathematical tabulation of common clinical signs and symptoms found in patients of acute appendicitis. It has been reported to be a cheap and quick diagnostic tool in patients with acute appendicitis. However, differences in diagnostic accuracy have been observed if the score were applied to various populations and clinical settings.

Age Distribution :Out of 55 patients studied in present series; the age incidence varies between 7 to 65 years. The maximum incidence of acute appendicitis was found in age group of 11-20 years $(45.45 \%)$; followed by age group of 21-30 years $(25.45 \%)$ and then of age group of 31-40 years (21.81\%). Approximately, $70 \%$ of the affected patients are in $2^{\text {nd }}$ and $3^{\text {rd }}$ decade of life. Similar finding was documented by Talukder et al (2009), and Kailash Singh et al (2008); that the maximum incidence of $67 \%$ in $2^{\text {nd }}$ and $3^{\text {rd }}$ decade of life. Both the authors have almost similar incidence of ratio and percentage in their series.

\section{Sex Distribution :}

Out of the 55 patients; $32(58.18 \%)$ were male and $23(41.81 \%)$ were females. The male : female ratio is 1.39:1.Similar results had been documented by Kailash Singh et al (2008) in their study, incidence of male and female was $55 \%$ and $45 \%$ respectively. Talukder DB et al (2009) also documented similar result with a male-female ratio of 1.38:1. M. Mardan (2007), documented different result in which the male:female ratio was 1:1.66. Shinji HIMENO et al (2003); also documented different results of male:female ratio is 1:1. The difference in the result may be due to racial and dietary and regional variations.

\section{Modified Alvarado Score :}

In our study in present series, we have divided the modified Alvarado scoring system in two groups. Firstly with a score $>7$ teremd as Modified Alvarado Score positive and secondly with a score $<7$ termed as Modified Alvarado Score negative. Out of 55 patients; 35 were considered positive (score >7) and they underwent appendicectomy irrespective of ultrasonographic finding.Patients who were scored negative for Modified Alvarado Score (Score <7); underwent appendicectomy on the basis of positive ultrasonographic findings. Out of the 20 patients with negative Modified Alvarado Score, 15 showed positive ultrasonographic findings and underwent appendicectomy. In present study; the sensitivity and specificity of Modified Alvarado Score is $82.05 \%$ and $81.25 \%$ respectively. Anand Rao et al (2007); documented similar results with a sensitivity and specificity of $88.8 \%$ and $75 \%$ respectively.Talukder et al (2009) also reported simlar sensitivity of $89 \%$.Pairat Srasorn (2008) documented sensitiviy and specificity of $98 \%$ and $92 \%$ respectively in their series of study.Alamgir et al (2009); reported the finding of sensitivity (94.14\%); which is in agreement with the present study but the finding of specificity was $66.66 \%$, which was lower than the finding of present study. David S. Wade et al (1993), AMA-Hashmey et al (2004), Siddiqui K et al (2007); reported their study; a sensitivity ranging from $52 \%$ to $62 \%$; which was lower than the finding of present study and a specificity with a similar result ranging between $78 \%$ to $82 \%$. R. Yegane et al (2008) documented low sensitivity (55\%) and specificity (59\%) and concluded that Modified Alvarado Score is neither sensitive nor specific for diagnosis of acute appendicitis. The present study; the positive and negative predictive value for Modified Alvarado Score is $91.42 \%$ and $65 \%$ respectively. The findings of the present study are similar to the findings of Davis. S. Wade et al (1993) with a positive and negative predictive value of $82 \%$ and $62 \%$ respectively. Pairat Srasom (2008) reported 
95\% positive predictive value of Modified Alvarado score in their series. Kailash Singh et al (2008) and Alamgir et al (2009) had documented 83\% positive predictive value and these are almost similar to the values of the present study. Srivastava et al (2004) reported low positive and negative predictive value of about $77 \%$ and $52 \%$; which is lower than the present study. The present study; the negative appendicectomy rate is $8.5 \%$.T.D. Owen et al (1992) are in agreement $(<10 \%)$ with the present study. I. Khan et al (2005), M. Mardan et al (2007), Talukder DB et al (2009) documented negative appendicectomy rate between $16 \%$ to $22 \%$, which is higher than this study.

\section{Ultrasonography :}

In our study in present series; the sensitivity and specificity of ultrasonography is $84.61 \%$ and $50 \%$ respectively. The positive and negative predictive value being $80.48 \%$ and $57.14 \%$ respectively and the negative appendicectomy rate being $19.51 \%$ by ultrasonography.Puylaert et al (1987); documented sensitivity of ultrasonography 75\%; which was lower than the findings of present series; but specificity was $100 \%$, which is higher than the present study. J.A. Worrel et al (1990); documented sensitivity and specificity of $68 \%$ and $98 \%$ respectively. Charles D. Douglous et al (2000) and Shinji Himeno et al (2003) documented sensitivity from $94 \%$ to $97 \%$ and specificity from $80 \%$ to $88 \%$.

\section{Comparative study of Modified Alvarado Score and Ultrasonography -}

David S. Wade et al (1993) has findings similar to the findings of present study by documenting sensitivity and positive predictive value of ultrasonography $85 \%$ and $88 \%$ respectively. Negative predictive value and specificity of ultrasonography was higher than present study. Specificity, positive and negative predictive value of Modified Alvarado Score documented by David. S. Wade et al (1993) was similar to present study. Siddique K et al (2007) reported low sensitivity both for ultrasonography (71\%) and Alvarado score (57\%). Hemant et al; documented similar positive predictive value $(93 \%)$ for modified Alvarado score to the present study but both sensitivity and negative predictive value was $40 \%$; which is lower than present study. On ultrasonography, sensitivity and positive predictive value reported by Hemant et al was $88 \%$ and $93 \%$; which was nearly similar to present study but specificity $(86 \%)$ and negative predictive value $(76 \%)$ was much higher than present study.

\section{Conclusion}

From present study, it is concluded that modified Alvarado score is better diagnostic tool than ultrasonography alone in diagnosis of acute appendicitis. But still, neither modified Alvarado score nor ultrasonography is absolute tool in reducing negative laparotomy in patients of suspected appendicitis. Although, ultrasonography alone has higher rate of negative appendicectomy than modified Alvarado score so positive ultrasonography cannot be prerequisite for appendicectomy in patients with suspected appendicitis. It can be only complimentary to clinical course or clinical judgment

References
[1]. Charles D Douglas et al, Randomised controlled trial of ultasonography in diagnosis of acute appendicitis, incorporating the Alvarado score BMJ, 2000, October 14; 321(7266): 919

[2]. Shrivastava UK et al, Evaluation of the Alvarado score in the diagnosis of acute appendicitis. Trop Gastroenterol 2004 Oct-Dec; 25(4) : 184-6.

[3]. Siddique K Evaluation of Modified Alvarado Score and Ultrasonography in Acute Appendicitis

[4]. Nasiri et al.Diagnostic values of ultrasound and the Modified Alvarado Scoring System in acute appendicitis;international Journal of Emergency Medicine 2012, 5:26 doi:10.1186/1865-1380-5-26

[5]. CarenDsouza,JohnMartis\&VinayVaidyanathan Diagnostic efficacy of modified alvarado score over gradedcompression ultrasonography; Nujhs Vol. 3, No.3, September 2013, ISSN 2249-7110

[6]. Ahmed M. Al-Hashemy et al. Appraisal of the modified Alvarado Score for acute appendicitis in adult Saudi Medical Journal 2004; Vol. 25(9); 1229-1231.

[7]. Alamgir et al, ACUTE APPENDICITIS : ROLE OF ALVARADO SCORING SYSTEM IN THE DIAGNOSIS Gomal Journal of Medical Sciences July-December 2009, Vol. 7, No. 2.

[8]. Alvarado A. A practical score for the early diagnosis of acute appendicitis, Ann. Emerg Med. 1986, 15 : 557-564.

[9]. Anand Rao Internet Journal of Surgery, 2007.

[10]. Bailey and Love's Short Practice of Surgery, $25^{\text {th }}$ edition, page 1204-18.

[11]. Balthazar EJ. Appendicitis : prospective evaluation with high-resolution CT. Radiology, 1991; 180: 21-24.

[12]. Behnam Sanei Evaluation of validity of Alvarado scoring system for diagnosis of acute appendicitis Pak J Med Sci April-June 2009, Vol. 25 No. 2 298-301.

[13]. Bhattacharjee PK, Chwdhury T, Roy D. Prospective evaluation of modified Alvarado score for diagnosis of acute appendicitis. J Indian Med Assoc. 2002, May; 100(5) : 310-1, 314. 
[14]. Chan MY, Tan C, Chiu MT, Ng YY. Alvarado score : an admission criterion in patients with right iliac fossa pain. The Surgeon : Surg J R Coll Surg Edinb Irel. 2003 Feb; 1(1) : 39-41.

[15]. Chan MY, Teo BS, Ng BL. The Alvarado score and acute appendicitis. Ann Acad Med Singapore. 2001, 30:510-12.

[16]. Charles D Douglas et al, Randomised controlled trial of ultasonography in diagnosis of acute appendicitis, incorporating the Alvarado score BMJ, 2000, October 14; 321(7266): 919.

[17]. David S, Wade et al, Accuracy of Ultrasound in the Diagnosis of Acute Appendicitis Compared With the Surgeon's Clinical Impression Arch Surg. 1993; 128(9): 1039-1046.

[18]. Fitz RH. Perforating inflammation of the vermiform appendix : with special reference to its early diagnosis and treatment. Am J Med Sci 1886; 92: 321-346.

[19]. J.A. Worrell Graded compression ultrasound in the diagnosis of appendicitis. A comparison of diagnostic criteria Journal of Ultrasound in Medicine, Vol. 9, Issue 3 145-150.

[20]. Kailash Singh et al, Application of Alvarado Scoring System in Diagnosis of Acute Appendicitis Vol. 10, No. 2, April-June 2008.

[21]. Kalam M, Talbot D, Cunliffe WJ, Rich AJ. Evaluation of the modified Alvarado Score in the diagnosis of acute appendicitis : a prospective study. Ann R Coll Surg Engl. 1994 Nov; 76(6); 418-9.

[22]. Kalan M, Rich AJ, Talbot D, Cunliffe WJ. Evaluation of the modified Alvarado score in the diagnosis of acute appendicitis : a prospective study. Ann R Coll Surg Engl 1994; 76 : 418-419.

[23]. Khan I et al, Application of Alvarado scoring system in diagnosis of acute appendicitis $\mathbf{J}$ Ayub Med Coll Abbottabad, 2005 Jul-Sep; 17(3) : 41-4.

[24]. Lucas Kidd Gwynn. The diagnosis of acute appendicitis; clinical assessment versus computed tomography evaluation. The Journal of emergency medicine, Volume 21, Issue 2, Pages 119-123 (August 2001).

[25]. M. M. Wani et al, Usefulness of The Alvarado Scoring System with Respect To Age, Sex and Time of Presentation, With Regression Analysis of Individual Parameters. The Internet Journal of Surgery, 2007 Volume 11 Number 2.

[26]. MAA Mardan et al. Role of ultrasound in acute appendicitis J Ayub Med Coll Abbottabad, 2007; 19(3).

[27]. Maingot's abdominal surgery, $11^{\text {th }}$ edition, page 589-90.

[28]. Malik AA, Wani NA. Continuing diagnostic challenge of acute appendicitis : evaluation through modified Alvarado Score. Aust N Z J Surg. 1998.

[29]. Nautial H. Combined use of modified Alvarado score in decreasing negative appendicectomy rate : US (JanFeb 2010), 72:42-48.

[30]. Nirajlal Baidya Evaluation of Alvarado Score in Acute Appendicitis. The Internet Journal of Surgery, 2007 Volume 9 Number 1.

[31]. Pairat Srasom, Application of Alvarado Scoring System in Diagnosis of Acute Appendicitis Compared with the Surgeon's Clinical Impression Arch Surg, 1993; 128(9): 1039-1046.

[32]. Puylaert et al, A prospective study of Ultrasonography in the Diagnosis of Appendicitis N Engl J Med 1987; 317: 666-669.

[33]. R. Yegane et al. Evaluation of Modified Alvarado score in acute appendicitis in Iranian Patients. Acta Medica Inranica 2008; 46(6); 501-506.

[34]. Schwart's Principles of Surgery, $8^{\text {th }}$ edition, page 1119-1125.

[35]. Shinji HIMENO et al. Ultrasonography for the Diagnosis of Acute Appendicitis Tokai J Exp Clin Med., Vol. 28, No. 1, pp. 39-44, 2003.

[36]. Shrivastava UK et al, Evaluation of the Alvarado score in the diagnosis of acute appendicitis. Trop Gastroenterol 2004 Oct-Dec; 25(4) : 184-6.

[37]. Siddique K Evaluation of Modified Alvarado Score and Ultrasonography in Acute Appendicitis.

[38]. T.D. Owen et al. Evaluation of the Alvarado score in acute appendicitis. J.R. Soc Med. 1992 February; 85(2) :87-88.

[39]. Talukder DB et al. Modified Alvarado Scoring system in the diagnosis of acute appendicitis JAFMC, Bangladesh, Vol. 5, No. 1 (June) 2009.

[40]. Teicher I, Landa B, Cohen M, Cabnick LS, Wise L. Scoring system to aid in the diagnosis of appendicitis. Ann Surg. 1983; 198:753-759. 